\title{
Inovações tecnológicas de embalagens nas indústrias de alimentos: estudo de caso da adoção de embalagem ativa em empresas de torrefação de café*
}

\author{
Aldara da Silva César \\ Universidade Federal Fluminense (UFF) \\ Cláudia De Mori \\ Embrapa Trigo e Universidade Federal de São Carlos (UFSCar) \\ Mário Otávio Batalha \\ Universidade Federal de São Carlos (UFSCar)
}

Recebido: 02/09/2008 Versão Revisada(entregue): 03/03/2009 Aprovado: 01/07/2009

\begin{abstract}
RESUMO
Grande parcela das inovações tecnológicas dos sistemas agroindustriais é gerada pelas "indústrias de apoio", grupo no qual as indústrias de embalagens se inserem. Esse artigo discute as inovações em embalagens destinadas à indústria de alimentos, em especial as chamadas embalagens ativas. Discute-se o caso de adoção da válvula unidirecional de alívio de gases, descrevendo a inovação e seus impactos em duas indústria processadoras de café nas empresas. A pesquisa desenvolvida é de ordem documental e qualitativo-descritiva de caráter empírica, usando técnica de análise de documentação indireta e estudo de caso . No caso abordado, a válvula possibilitou a diversificação da linha de produtos e o incremento da sua qualidade, não havendo complicações no que se refere ao repasse do custo adicional para o consumidor desse produto. Contudo, verifica-se que esse custo adicional da adoção da tecnologia dificulta a difusão da válvula em produtos similares.
\end{abstract}

* Os autores agradecem aos pareceristas, que deram indicações valiosas para a melhoria deste trabalho. 
Palavras-Chave | Inovaçōes; Setor de Embalagem; Embalagem Ativa; Válvula Unidirecional de Alívio de Gases; Café.

CÓdigos JEL | O14; O33

\section{Technological Innovations in the Food Packaging: a case study of adoption of active packaging in coffee roaster companies}

\section{ABSTRACT}

Most of technological innovations in agro-food systems are created by "supporting industries", the group where packaging industries are inserted. This article presents the packaging innovations used in food industries, particularly, the active packaging. This paper deals with an adoption case of a degassing one-way valve, describing this innovation and its impacts in two coffee companies. This study can be classified as a documental, qualitative-descriptive and empirical research, using indirect documentation technique and case study analysis. According to this case, the valve made possible the diversification of the company product line and product quality improvement. There were no complications involving an additional cost to the customers. However, it has been observed that this additional cost from technology adoption makes difficult the diffusion of this valve in other similar products.

KEYWORDS I Innovation; Packaging Sector; Active Packaging; Degassing One-way Valve; Coffee.

JEL CODES: O14; O33

\section{Introdução}

Existe um consenso entre as diversas áreas de conhecimento sobre a importância da inovação na competitividade de um setor ou nação. Adam Smith, já no século XVIII, afirmava que a divisão de trabalho e a ampliação do mercado estimulavam as inovações tecnológicas e que estas se revertiam em ganhos reais de competitividade (FREEMAN; SOETE, 1997). No âmbito da firma, a competitividade pode ser entendida como "a capacidade da empresa formular e implementar estratégias 
concorrenciais que lhe permitam ampliar ou conservar, de forma duradoura, uma posição sustentável no mercado" (SILVA; BATALHA, 1999). Segundo Santini (2006), as empresas que desejam manter ou ampliar suas posiçóes de mercado devem ser ágeis na capacidade inovativa. Arundel (1998) também postula que a habilidade de inovar rapidamente é essencial para o posicionamento competitivo das mesmas. Apesar de apresentar menor dinamismo tecnológico quando comparado a outros setores da economia, o ramo de produção de alimentos também tem na tecnologia e na inovação aspectos essenciais para a competitividade das suas empresas.

Pinto e Anholon (2004), em pesquisa realizada com algumas empresas de expressão nos mercados brasileiro e internacional, relatam as divergências e a preocupação das organizações em tentar mensurar o processo de inovação e estabelecer a real contribuição desse desempenho para a competitividade de suas atividades. No entanto, a valoração de recursos intangíveis, tais como a inovação, raramente reflete de forma direta no lucro das organizações. De acordo com Becker e Huselid (1998, apud KAPLAN; NORTON, 2001), os recursos indiretos proporcionam reações em cadeia de causa e efeito que tornam, muitas vezes, impossível tal mensuração nos resultados financeiros da empresa. No caso da indústria de alimentos (IA), a maior parcela das inovaçōes tecnológicas é gerada pelas "indústrias de apoio", grupo no qual se inserem as indústrias de embalagens.

Para discutir as inovações de embalagens destinadas à indústria de alimentos, este artigo lança mão de estudos de caso em empresas torrefadoras de café que adotaram uma tecnologia de válvula unidirecional de alívio de gases, descrevendo a inovação e seus impactos nestas empresas. $\mathrm{O}$ texto está dividido em cinco seçôes, além desta introdução. A segunda seção traz a descrição do procedimento metodológico e a terceira discorre sobre aspectos relacionados à inovação na IA, apresentando tendências para inovaçōes no setor, com destaque para o caso das embalagens ativas. A quarta aborda a adoção da embalagem com uso de válvula unidirecional de alívio de gases via estudos de caso realizados em duas indústrias de torrefação de café, analisando o impacto do emprego desta tecnologia nas empresas. Finalmente, a quinta seção traz as considerações finais.

\section{Procedimentos metodológicos}

A pesquisa conduzida para elaboração deste artigo é de caráter documental e qualitativo-descritiva. Para delimitar o estado da arte de inovação na IA e no setor 
de embalagens, realizou-se uma pesquisa documental indireta por meio de fontes bibliográficas e documentos.

Já para análise da adoção de inovação em embalagem, esse trabalho faz uso de abordagem descritiva, que tem por finalidade observar, registrar e analisar determinadas características de populações ou fenômenos (JUNG, 2003), bem como de abordagem qualitativa, cuja principal característica é a ênfase na perspectiva do indivíduo em estudo (BRYMAN, 1989). Neste quadro de investigação qualitativo descritiva, empregaram-se o estudo de caso, como método de procedimento, e a entrevista, como técnica de pesquisa. Tull (1976) afirma que "um estudo de caso refere-se a uma análise intensiva de uma situação particular" e Bonoma (1985) coloca que o "estudo de caso é uma descrição de uma situação gerencial". A pesquisa compreendeu a realização de dois estudos de casos de adoção de embalagem ativa, visando identificar similaridades e complementaridades para robustecer a interpretação do fenômeno estudado.

O instrumento escolhido para a coleta de dados foi o questionário semiestruturado com entrevista presencial. Segundo Forza (2002), este procedimento se destaca pela vantagem de permitir flexibilidade no sequenciamento das questôes propostas. $\mathrm{O}$ roteiro de entrevistas abordou questôes relacionadas a: (a) dados gerais de caracterização da empresa; (b) a inovação em estudo (motivação para adoção, fonte de informação, fornecedor da inovação e tecnologias similares ou substitutas); (c) processo de implantação da inovação e as mudanças requeridas para isso (descrição do processo, alterações em termos de layout, equipamentos, linha de produção, necessidade de contratação e treinamento de recursos humanos, geração de resíduos no processo, entre outros aspectos); (d) impactos em termos de qualidade; (e) custos de implantação e financiamento; (f) exclusão ou diversificação de produtos; (g) possíveis alteraçôes na política de vendas, agregação de valor e faturamento das empresas. Na empresa A foram entrevistados a diretora comercial, um encarregado da produção e o provador de café, o qual assina como responsável técnico da empresa e também auxilia no setor da produção. Já na empresa B, foram entrevistados o gerente comercial e o responsável pelo setor industrial.

Para a descrição da inovação, também foram realizados contacto com distribuidores da inovação em estudo no Brasil, análise de documentos formais e informais sobre a inovação e consulta à base de patentes. As informações coletadas foram analisadas de modo a descrever e sumarizar as características da inovação e seus impactos sobre o sistema produtivo das empresas e sobre o produto comercializado. 


\section{Inovação tecnológica na indústria de alimentos e no setor de embalagem}

Esta seção apresenta alguns conceitos gerais sobre inovação, tece considerações acerca da dinâmica inovativa na IA e descreve as principais inovaçôes recentes no setor de embalagem.

\subsection{Inovação: conceitos e caracterização}

Zaltman, Duncan e Holbeck (1971) definem inovação como "qualquer idéia, prática ou artefato material percebido como novo pela unidade de adoção relevante, a qual pode ser uma pessoa, uma organização, um setor industrial, uma região, etc.". Já para Dosi (1988), inovação pode ser entendida como "a busca, a descoberta, a experimentação, o desenvolvimento, a imitação e a adoção de novos produtos, novos processos e novas técnicas organizacionais".

Segundo Schumpeter (1988), o processo inovativo consiste em três fases sequenciais: a invenção, a inovação e a difusão. A invenção é o processo da descoberta de princípios técnicos novos que podem ter ou não potencial de exploração comercial. Já a inovação, corresponde ao processo de desenvolvimento da forma comercial de uma invenção específica. Após sua geração, a difusão relaciona-se à expansão dessa inovação em uso comercial, sob a forma de novos produtos e processos. Para o autor, há cinco tipos de atividades de inovação: um novo produto; um novo processo; abertura de um novo mercado; acesso a novos recursos para o processo produtivo; e estabelecimento de uma nova organização.

As inovaçôes podem ainda ser caracterizadas em função do objeto de mudança, do grau de dependência de outras inovações, do tipo de mudança, da abrangência do grau de inovatividade, entre outras dimensões. De acordo com o Manual de Oslo (OECD, 2005), os tipos de inovação tecnológica podem ser divididos em duas dimensōes: inovação incremental e radical. A primeira, bastante difundida na IA, é definida como um aprimoramento técnico de base contínua sem, contudo, alterar a estrutura industrial da empresa. Já a inovação radical, como o próprio nome sugere, representa uma grande mudança estrutural no padrão tecnológico vigente, o que pode muitas vezes resultar em novas indústrias, setores ou mercados.

Com relação à abrangência do grau de inovatividade, Furtado e Carvalho (2005) e Booz, Allen e Hamilton (1982, apud ILORI, OKE e SANNI, 2000) classificam 
novos produtos segundo duas categorias: "novo para o mercado", ou seja, um produto totalmente novo; e "novo para a empresa", quando esta lança um produto já existente no mercado. Já Fuller (1994), no que se refere ao desenvolvimento de um novo produto, apresenta uma caracterização direcionada à indústria de alimentos (IA), classificando as inovações em sete classes: extensões de linhas; reposicionamento de produtos existentes; nova forma de produtos existentes; reformulação de produto existente; nova embalagem para produto existente; produtos inovadores; e produtos inteiramente novos.

Entre as diversas atividades inovativas, as de Pesquisa e Desenvolvimento (P\&D) influenciam ativamente o processo de inovação tecnológica das empresas (STAL, 2007). Kumpe e Bolwijn (1994) classificam as atividades de P\&D como elementos essenciais para o alcance da eficiência, da qualidade e da flexibilidade de empresas inovativas. Por outro lado, Bossi (2003) enumera alguns pontos que tolhem os investimentos das organizações em atividades de P\&D. Este autor cita o custo e o maior interesse em pesquisas de curto prazo como alguns destes fatores que dificultam o comprometimento das empresas com pesquisas mais elaboradas e de longo prazo. $\mathrm{O}$ autor menciona, ainda, certo comodismo por parte de grandes empresas em posição de liderança, tendo em vista que o resultado do esforço inovativo nem sempre corresponde às expectativas e nem sempre a maior beneficiada é a empresa que gerou a inovação, pois, em determinadas situações, o processo de cópia é muito mais ágil do que o de desenvolvimento em si.

Por outro lado, Santini (2006) enumera alguns dos principais fatores que motivam a inovação dentro de uma organização: objetivos de mercado da empresa, como metas de extensão de mercados ou mesmo a própria sobrevivência nele; preocupação constante com a redução de custos; objetivos relacionados à qualidade dos produtos e às condições de trabalho; diminuição de impactos ambientais; exploração de uma oportunidade de negócio ou outros fatores microeconômicos (capacidade interna da empresa para inovar, período de retorno de investimento, etc.), mesoeconômicos (dinamismo do setor, perfil do consumidor diante de inovaçôes, etc.) e macroeconômicos (legislações e regulamentações, informações sobre mercado, etc.). De acordo com a OECD (2005), podem-se distinguir dois grupos de fontes de informação de inovação para a empresa: interna (departamento de P\&D e demais áreas da empresa) e externa (instituições públicas de pesquisa, fluxo tecnológico interfirma e interindústria, concorrentes, clientes ou consumidores, empresas de consultoria e fornecedores de equipamentos e matérias-primas). 


\subsection{Dinâmica inovativa na indústria de alimentos}

A IA necessita adaptar-se às mudanças do comportamento dos consumidores, os quais vêm demandando produtos cada vez mais relacionados à boa forma, à saúde, à conveniência e à preocupação ambiental, sem negligenciar a importância da segurança do alimento ingerido. Assim, o processo de desenvolvimento de produto deve considerar essas diferentes informaçōes no projeto, de forma que tais anseios do mercado sejam incorporados ao produto. Isso sem descuidar de aspectos como preço, qualidade e rapidez de lançamento de produtos e serviços no mercado.

Segundo Pavitt (1984), atividades agropecuárias e agroindustriais apresentam padrão concernente a setor dominado por fornecedores e de menor dinamismo tecnológico, embora, para o autor, a indústria de alimentos seja caracterizada como setor intensivo em escala. $\mathrm{Na}$ verdade, as inovaçôes tecnológicas referentes ao setor agropecuário geralmente não são desenvolvidas pelos agricultores ou pecuaristas, mas sim pelos setores de material genético vegetal, defensivos agropecuários, alimentação animal, máquinas e equipamentos, etc. De forma análoga, grande parte das inovações da IA provém de diferentes setores, tais como os segmentos de maquinários e equipamentos, de aditivos e de embalagens, este último foco do presente artigo.

$\mathrm{Na}$ indústria de alimentos, segundo Cabral (2001), observa-se um paradoxo dado pela baixa intensidade de investimento em $P \& D$ e alta intensidade inovativa (produto e processo). Para o autor, esta situação pode ser explicada pelas noções de inércia de consumo, inovação incremental de produto e redundância tecnológica. Ainda de acordo com o autor, há uma constante demanda por novos produtos no setor de alimentos. No entanto, devido aos padrōes conservadores dos consumidores em relação às questôes alimentares, tem-se um padrão de consumo estático, uma vez que as características do novo produto devem ser similares às daqueles existentes. Com isso, poucas rupturas tecnológicas são verificadas. Acrescenta-se o fato de que grande parte do conhecimento científico-tecnológico usado origina-se em indústrias correlacionadas.

Os resultados obtidos na Pesquisa de Inovação Tecnológica - Pintec (IBGE 2002, 2005 e 2007) demonstram que as atividades de inovação tecnológica no setor de alimentos apresentam-se próximas ao padrão da indústria brasileira, com taxas de inovação de 29,2\% no triênio $1998-2000,33,6 \%$ no período $2001-2003$ e 31,9\% em 2003-2005. As inovações em processo ou simultaneamente em produto e processo são as de maior incidência entre as empresas do setor, sendo que a maioria 
das inovações de produto ou de processo representa novidade somente para a empresa. Com relação aos dispêndios em atividades inovativas proporcionais à receita líquida de vendas, os dados da Pesquisa evidenciam que as atividades ligadas ao setor de alimentos apresentam valores menores do que a média da indústria brasileira total e da indústria de transformação, nos três períodos, com redução dos valores percentuais no transcorrer das três ediçōes da pesquisa. As despesas realizadas em atividades de inovação pelo setor foram da ordem de $1,7 \%$ a 2,3\% da receita líquida de vendas. A aquisição de máquinas e equipamentos representou o maior percentual de gastos entre as diferentes atividades inovativas, representando 58,9\% do total de dispêndios em atividades inovativas na média das três ediçōes da pesquisa. $\mathrm{O}$ setor de alimentos apresenta baixo investimento em atividades internas de $\mathrm{P} \& \mathrm{D}$, com valores de $0,22 \%, 0,10 \%$ e $0,13 \%$ da receita líquida de vendas, respectivamente, em 2000, 2003 e 2005.

\subsection{Setor de embalagem e as inovações tecnológicas}

As embalagens têm como principal função conter, manter e conservar alimentos por intermédio do maior isolamento do produto com o meio externo. A substituição do escambo pela moeda facilitou a transação de mercadorias e resultou na necessidade de desenvolvimento de embalagens que permitissem transportá-las para pontos cada vez mais distantes e distintos, com o mínimo de perdas em quantidade e qualidade.

Vale lembrar que centenas de milhões de pessoas são contaminadas por doenças veiculadas por alimentos - DVAs anualmente (FAO/WHO, 2002). De acordo com o Centers for Disease Control and Prevention (2005), as DVAs vitimam 76 milhões de pessoas todo ano nos EUA, das quais 300 mil ficam hospitalizadas e 5 mil morrem. O custo médico deste problema chega a atingir US\$ 7 bilhões, acarretando uma perda de produtividade ao redor de US\$ 37 bilhões. Já no Brasil, segundo os dados do Sistema de Informações Hospitalares (SIH), do Ministério da Saúde, ocorreram, em média, 568.341 internaçôes por ano em decorrência de DVAs, entre 1999 e 2004, com um custo médio anual de R \$ 46 milhões. De acordo com o Sistema de Informação sobre Mortalidade (SIM), de 1999 a 2002, ocorreram 25.281 óbitos por DVAs, uma média de 6.320 mortes/ano (MINISTÉRIO DA SAÚDE, 2005). No entanto, a notificação de casos de DVAs no Brasil é muito mais baixa da ocorrência real, visto que a maior parte da população se automedica e consulta um médico apenas em situações graves. 
Inúmeros pesquisadores têm se dedicado a estudos de conservação dos alimentos que visam anular a potencialidade de transmissão de doenças e minorar as causas de degradação da qualidade dos produtos alimentícios. As perdas de qualidade dos alimentos variam de acordo com a sua composição (atividade de água, $\mathrm{pH}$, composição lipídica, etc.), das condições de estocagem (temperatura, umidade relativa e concentração de oxigênio) e propriedades das embalagens (volume, composição do espaço livre, propriedades de barreiras, etc.) (ALLARCON; HOTCHKISS, 1993). Além da preocupação em manter a segurança do alimento, as novas embalagens também devem considerar um mercado que busca, cada vez mais, produtos que se aproximem da sua forma natural de frescor e qualidade (VERMEIREN et al., 1999; ROONEY, 1995).

Ao longo das décadas, as embalagens adquiriram a função de comunicação do produto com o consumidor, levando a área de marketing a desenvolver embalagens que permitissem aumentar o interesse do consumidor pelo produto. Várias pesquisas apontam a importância da embalagem na decisão de compra dos consumidores, visto que a maioria dos entrevistados associa a embalagem à qualidade do produto em si (MESTRINER, 2005). No Brasil, a qualidade da embalagem é fator determinante para o sucesso da venda do produto em níveis maiores do que os encontrados nos mercados norte-americanos e europeus (SOUZA; VASCONCELOS, 2000). Outra característica incorporada nos projetos de desenvolvimento de embalagens refere-se à praticidade. A maior valorização do atributo conveniência no momento da compra acentua a importância desta característica.

O setor de embalagens vem ganhando importância econômica ao longo dos anos. A participação da indústria de embalagens no Produto Interno Bruto (PIB) de cada país encontra-se na faixa de $0,5 \%$ a 2,5\%, segundo a Organização Mundial de Embalagem (WPO). O faturamento dessa indústria no Brasil vem alcançando valores ascendentes, atingindo $\mathrm{R}$ \$ 20,43 bilhōes em 2002, $\mathrm{R}$ \$ 24,27 bilhōes em 2003, R \$ 28,60 bilhões em 2004 e R \$ 31,30 bilhões em 2005 (MORAES, 2006). Somente as embalagens ativas, controladas e inteligentes, movimentam cerca de US\$ 38 bilhões nos EUA, estimando-se que esse valor ultrapasse a marca de US\$ 54 bilhões em 2008 (ETC GROUP, 2004)As inovações tecnológicas no setor de embalagens têm procurado transpor o conceito tradicional de embalagem, no qual a mesma é vista apenas como uma barreira inerte que confina o alimento para impedir qualquer interação entre o produto e o meio externo. Esse novo conceito de embalagem caracteriza-se por apresentar inovações tecnológicas que, além de 
proteger, interagem com o produto de forma benéfica e agregam valor ao produto, o que pode ocorrer pelo incremento da qualidade do alimento (das propriedades sensoriais, atributo de segurança, etc.) ou pelo aumento da vida de prateleira (shelf life). Nas últimas décadas, vários estudos têm sido conduzidos com ênfase neste novo conceito, destacando-se aqueles relacionados às denominadas embalagens ativas, foco do estudo de caso deste artigo.

As embalagens ativas vêm sendo empregadas com sucesso nos EUA, Japão e Austrália. Apesar da expansão desse segmento na Europa, esse tipo de inovação ainda é limitado. Restrições na legislação, medo ou resistência do consumidor e necessidade de maior conhecimento sobre os impactos econômicos e ambientais das mesmas estão entre os fatores que obstaculizam a difusão deste tipo de embalagem (KRUIJF et al, 2002). No Brasil, o Instituto de Tecnologia de Alimentos (Ital), a Universidade Estadual de Campinas (Unicamp), o Centro de Tecnologia de Embalagem (Cetea) em cooperação com a Faculdade de Engenharia Química da Unicamp, o Departamento de Tecnologia de Alimentos da Universidade Federal de Viçosa (UFV) e o Laboratório Nacional de Nanotecnologia para o Agronegócio (LNNA/Embrapa) têm se destacado em pesquisa e desenvolvimento de embalagens ativas.

Estas embalagens são definidas como sistemas que mudam a condição de acondicionamento do alimento para estender sua vida de prateleira ou aumentar sua segurança ou propriedades sensoriais, mantendo a qualidade do produto. Esta definição foi preconizada pelos participantes da European FAIR project CT-98-4170 "Evaluating safety, effectiveness, economic-environmental impact and consumer acceptance of active and intelligent packagings" (SOARES et al., 2004). Em outras palavras, embalagens ativas são mecanismos que interagem e mitigam fatores que afetam negativamente a qualidade do produto, contribuindo para sua degradação ou ainda facilitando a transmissão de doenças. Assim, as embalagens ativas procuram corrigir limitaçôes das embalagens convencionais (OLIVEIRA; OLIVEIRA, 2004).

São exemplos de embalagens ativas: absorvedores de oxigênio; absorvedores de etileno; eliminadores de $\mathrm{CO}_{2}$; emissores de $\mathrm{CO}_{2}$; enzimas; controladores de umidades; controladores de sabor; controladores de odor; agentes antimicrobianos; antioxidantes; propriedades microbiológicas; liberadores de etanol; preservadores de cor; revestimentos comestíveis; e materiais autorresfriantes ou autoaquecedor. Para ilustrar, o Quadro 1 descreve alguns tipos de embalagens ativas. 
QUADRO 1

Descrição de alguns tipos de embalagens ativas

\begin{tabular}{|c|c|}
\hline $\begin{array}{c}\text { Tipo de } \\
\text { embalagem ativa }\end{array}$ & Descrição \\
\hline $\begin{array}{l}\text { Embalagem } \\
\text { absorvedora de } \\
\text { etileno }\end{array}$ & $\begin{array}{l}\text { Embalagens plásticas à base de poliolefinas e de poliamidas, com } \\
\text { minerais incorporados na massa de polímero, que atuam como } \\
\text { absorvedores de etileno e visam controlar o teor desse composto } \\
\text { no espaço livre da embalagem ao redor do produto, reduzindo } \\
\text { seu metabolismo e, consequentemente, aumentando sua vida de } \\
\text { prateleira (MORAES, 2006). Comumente são empregadas para } \\
\text { frutas. }\end{array}$ \\
\hline $\begin{array}{l}\text { Embalagem com } \\
\text { absorvedores de } \\
\text { oxigênio }\end{array}$ & $\begin{array}{l}\text { Embalagens que possuem absorvedor de oxigênio incorporado na } \\
\text { camada intermediária do filme plástico. A embalagem mantém } \\
\text { comportamento passivo atéserativada duranteo acondicionamento, } \\
\text { quando atua oxidando o polímero, o que resulta no consumo do } \\
\text { gás quando acondicionado com radiação ultravioleta. Outras } \\
\text { variantes incorporam sachets, rótulos ou cartôes que desempenham } \\
\text { esse papel de absorvedor. Atualmente, os absorventes mais usados } \\
\text { comercialmente estão disponíveis na forma de sachets com agentes } \\
\text { redutores, como óxido de ferro, carbonato ferroso ou outros } \\
\text { compostos ferrosos e platina (MORAES, 2006). Utilizado em } \\
\text { carnes, frutas, legumes, biscoitos e pães e cervejas. }\end{array}$ \\
\hline $\begin{array}{l}\text { Embalagem } \\
\text { liberadora de } \mathrm{CO}_{2}\end{array}$ & $\begin{array}{l}\text { Embalagens que contêm válvula de alívio de gases, o que evita } \\
\text { reaçōes de oxidação e rancificação e permite a manutenção de } \\
\text { aroma e sabor. Empregadas em café torrado. }\end{array}$ \\
\hline $\begin{array}{l}\text { Filme com } \\
\text { incorporação de } \\
\text { enzimas }\end{array}$ & $\begin{array}{l}\text { Enzimas podem ser incorporadas nas embalagens dos produtos } \\
\text { para a obtenção de resultados bastante específicos. Como exemplo, } \\
\text { cita-se a incorporação da enzima naringinase ao filme plástico da } \\
\text { embalagem interna de caixinha do suco de uva para redução do } \\
\text { sabor amargo da bebida. Tal procedimento substitui o processo } \\
\text { convencional de retirada de amargor da bebida que é muito lento } \\
\text { e mais custoso (FAPEMIG, 2004). Outros exemplos: filme com } \\
\text { lactase para modificação da lactose presente no leite, tornando o } \\
\text { produto próprio para pessoas intolerantes a esse açúcar (CUNHA, } \\
\text { 2007); adição de glicose oxidase e catálise ao filme para a remoção } \\
\text { de oxigênio e de compostos de degradação microbiológica; e, } \\
\text { ainda, o uso de enzimas modificadas de colesterol para promover } \\
\text { a hidrólise do colesterol em produtos com altas percentagens desse } \\
\text { composto (BROODY; BUDNY, } 1995 \text { apud CRUZ, 2000). }\end{array}$ \\
\hline $\begin{array}{l}\text { Filme com } \\
\text { incorporação de } \\
\text { conservantes }\end{array}$ & $\begin{array}{l}\text { Incorporação de substâncias conservantes, tais como propionato } \\
\text { e sorbato em embalagem para pão de forma; de nisina em } \\
\text { embalagem para queijo e de lactato de sódio em embalagem para } \\
\text { salsicha (SOARES, 2007). }\end{array}$ \\
\hline
\end{tabular}




\section{Estudo de caso}

\subsection{Identificação e desenvolvimento da inovação}

A válvula unidirecional de alívio de gases, ${ }^{1}$ também chamada de válvula de desgasificação unidirecional, consiste em mecanismo capaz de modificar o ambiente interno da embalagem por meio da expulsão do gás carbônico produzido pelo alimento embalado (Figura 1). Este gás, quando não eliminado, compromete o sabor e aroma do produto e causa estufamento da embalagem, o que dificulta as operações de logística. Suas principais vantagens são: acondicionamento e bloqueio de aromas no interior da embalagem; permitir a saída de $\mathrm{CO}_{2}$, mas não a entrada de oxigênio; e fácil aplicabilidade em linha de produção.

A inovação original foi desenvolvida pela empresa italiana Goglio, na década de 1960. Localizada em Milão e fundada em 1850, hoje com 1.427 funcionários e nove plantas industriais na Europa, EUA e China, a empresa fornece desde embalagens diversas e válvulas de escape de gases até maquinários para o envase dos produtos.

A inovação possui registro de patente em vários países e blocos econômicos, tais como Itália, EUA, Canadá, Japão, Brasil e União Europeia. No Brasil, o depósito de pedido de patente foi feito em 1994.

FIGURA 1

Embalagem com válvula unidirecional de alívio de gases: detalhe do mecanismo
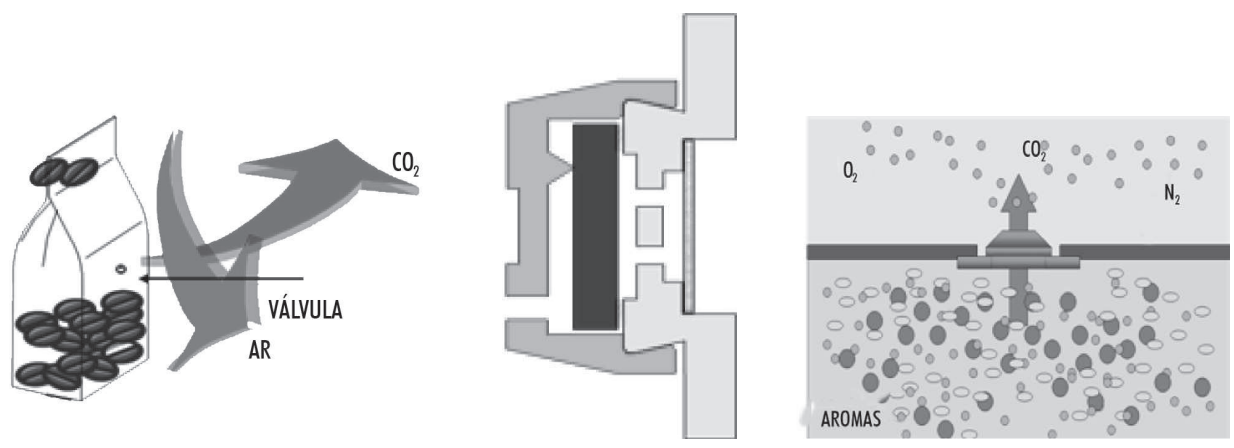

Fonte: Laboratório Chimico - Atlantics Foods.

1. Em inglês, degassing one-way valve. 
No Brasil, a válvula é distribuída por uma empresa importadora que possui parceria com aquela detentora da inovação. A operação de colocação da válvula em embalagem convencional de café expresso, transformando-a em uma embalagem ativa, cabe às empresas de embalagens ou à própria torrefadora. De acordo com essas empresas, o custo para a conversão da embalagem (isto é, custo da válvula e processo de colocaçãa) é de 76 euros por milheiro. Considerando-se a cotação de cada euro a $R \$ 3,07$ em 23/03/2009, esse custo é de $R \$ 233,33 /$ milheiro ou $\mathrm{R} \$ 0,23$ por embalagem.

Vale destacar que existem no mercado brasileiro válvulas de alívio de gases similares àquela desenvolvida pela Goglio. No entanto, aspectos tecnológicos, como a ausência de carvão ativado na válvula, reduzem a eficiência do mecanismo. Há também outras opções disponíveis, como a válvula bidirecional que permite a troca de gases e os sachets absorvedores de gás $\mathrm{O}_{2}$ e $\mathrm{CO}_{2}$ feitos de pó de ferro próprios para esse produto.

\subsection{Os impactos da inovação}

O estudo sobre a adoção da referida inovação foi realizado em duas empresas de torrefação de café. A seguir apresentam-se informaçōes sobre as empresas entrevistadas, processo de adoção da inovação e as implicações decorrentes.

\section{Empresa A}

A indústria de torrefação de café $\mathrm{A}$ atua a mais de meio século no mercado e pode ser caracterizada como uma empresa familiar de pequeno porte, com faturamento equivalente a R \$ 9 milhôes em 2007. Localizada na região sul do Estado do Rio de Janeiro, destina 95\% da sua produção para o mercado regional. O restante (5\%) é direcionado para a região litorânea do Estado de São Paulo e Vale do Paraíba. A empresa tem buscado a melhoria contínua da qualidade do produto por meio da comercialização de um produto $100 \%$ arábico e pela busca de certificações, tais como o selo de Qualidade do Programa de Qualidade do Café, da Associação Brasileira da Indústria de Café (Abic), selo da Abrinq e ISO 9000. Além disso, também têm ocorrido investimentos em promotores de venda no varejo, promoçôes, SAC e propagandas regionais em out doors e rádios. Tais ações, segundo a empresa, têm grande importância para estreitar o relacionamento com o consumidor e garantir sua fidelidade. 
A empresa não realiza investimentos em pesquisa e desenvolvimento de novos processos e produtos. As informações sobre os avanços tecnológicos são obtidas em revistas especializadas e, principalmente, por meio de visitas de representantes comerciais e fornecedores.

Entre os produtos disponibilizados pela indústria no mercado, estão o café torrado e moído em embalagem tipo almofadinha (100, 200 e 250 gramas), café torrado e moído embalado a vácuo (250 e 500 gramas), café torrado em grão para espresso em embalagem de papel kraft ( $5 \mathrm{~kg}$ ) ou com envoltório de poliéster, polietileno e alumínio com válvula unidirecional $(1 \mathrm{~kg})$ e, por fim, cappuccino tradicional (300 gramas) e light (210 gramas). Para o presente trabalho, destaca-se o café torrado em grãos ofertado para o mercado de café espresso, cuja embalagem caracteriza-se por possuir válvula de alívio de gases unidirecional para expulsão do gás carbônico, que é liberado pelo café nas primeiras 24 horas após a torração.

A válvula unidirecional foi apresentada à empresa por indicação do fornecedor de embalagens e vem sendo usada há dez anos, o que representa certa consolidação do produto no mercado que atua. A empresa decidiu adotar a válvula com o propósito de alcançar maior qualidade do produto e atender a um segmento diferenciado e em expansão.

Segundo os entrevistados, o processo de implantação dessa tecnologia foi bastante simples, não requerendo nenhuma adaptação na linha de produção da empresa. A válvula é adquirida separadamente e a operação de inserção na embalagem é feita pelo distribuidor de embalagem, sem custos adicionais para a empresa. Não houve necessidade de aquisição de financiamento para implantação do sistema.

A válvula unidirecional possibilitou a diversificação da linha de produtos oferecida pela empresa, que passou a atuar com um produto de qualidade superior em um segmento de mercado diferenciado: o de café espresso de domicílio. Com a nova embalagem, a empresa evidenciou uma preocupação não somente com a apresentação do seu produto, mas também com sua qualidade, atributo valorizado e valorado por esse segmento. Isso proporcionou agregação de valor ao café comercializado e permitiu à empresa se manter nesse mercado, já que a válvula vem sendo empregada pelos seus concorrentes.

Os consumidores desse produto, representados principalmente pelas classes A e B, são clientes considerados exigentes e se mostram dispostos a pagar um pouco mais para desfrutar de um produto de melhor qualidade. O custo adicional referente à adoção dessa nova tecnologia, equivalente a $1,9 \%$ e $1 \%$ do preço final respectivo dos produtos de embalagens $250 \mathrm{~g}$ e $500 \mathrm{~g}$, foi transferido ao preço do produto final. 
Hoje esse produto responde por 3,1\% do faturamento total da empresa e, segundo a diretora comercial, tende a aumentar.

De acordo com os entrevistados, a introdução do uso da válvula permitiu estender a vida de prateleira do café espresso para um ano, enquanto sem a válvula a validade era de apenas um mês. Isto resultou em alteração no planejamento da produção e otimização de uso de recursos humanos e dos períodos de produção, uma vez que o café espresso passou a ser produzido em espaços maiores de tempo, em decorrência da extensão de validade.

Para os entrevistados, não há motivação para o uso da válvula em produtos de menor valor agregado. A tecnologia encarece o custo do produto, o que reduziria a competitividade de produtos mais baratos e tradicionais, como o almofadinha, por exemplo, para o qual qualquer centavo adicional afeta a decisão do consumidor. Neste estudo não se realizou uma comparação detalhada de custos e ganhos obtidos na adoção da tecnologia considerando os demais produtos da empresa. No entanto, ressalta-se que a ausência de cálculos que considerem os ganhos indiretos, tais como maior tempo de prateleira, melhor qualidade e otimização do uso de recursos produtivos, alude tacitamente que o uso da embalagem valvulada é alto para dado produto e desconsidera que os ganhos indiretos poderiam viabilizar sua adoção em produtos de menor valor de mercado.

\section{Empresa $B$}

Localizada na região sudeste do Estado de São Paulo, a indústria de torrefação de café B foi fundada em 1930 e tem foco no mercado regional. Trata-se de empresa de porte médio, com 54 funcionários e um faturamento equivalente a $R$ \$ 19 milhôes por ano. A empresa possui duas unidades de processamento, em que são processadas 300 toneladas de café por mês. A planta industrial onde se efetuou a coleta de dados foi instalada em 1978, por ocasião da transferência da unidade da regiāo central da cidade para nova área industrial municipal. A empresa, que atende a diferentes segmentos de mercado (tradicional, superior, gourmet e orgânico), com ampla oferta de produtos, demonstra preocupação com a melhoria de qualidade, dispondo de sistema ISO 9001:2000 desde 2001 e integrando o Programa de Qualidade do Café da Abic, com certificação Gourmet para as marcas de café espresso e Certificação Superior para uma marca de café torrado e moído. O café orgânico possui certificação pela BSC Öko-Garantie e Organização Internacional Agropecuária - OIA. A empresa também possui um setor de locação e venda de máquinas para café espresso, direcionado para escritórios, indústrias, clínicas, 
prestadores de serviços e outros estabelecimentos, ofertando serviços de instalação, assistência técnica e venda de insumos, além de prestar serviços de processamento de café (torrefação, moagem e empacotamento) para terceiros. Essa multiplicidade de segmentos de mercados atendidos, produtos e atividades denota o uso de estratégia de diversificação via produto e mercado.

A empresa possui laboratório de análise de rotina para controle de qualidade, mas não realiza atividades internas de $\mathrm{P} \& \mathrm{D}$ para desenvolvimento de novos processos e produtos. As fontes de informaçôes sobre tecnologia são os fornecedores e representantes comerciais, participações em congressos, feiras e exposiçôes, revistas especializadas e observação da concorrência.

A linha de produtos da empresa compreende: café torrado e moído em embalagem tipo almofadinha (250 e 500 gramas); café torrado e moído embalado a vácuo (250 e 500 gramas); café torrado e moído orgânico embalado a vácuo (250 gramas); café torrado em grãos em embalagem stand-up para moagem na hora (500 gramas); café torrado em grãos em embalagem com válvula unidirecional (500 gramas e $1 \mathrm{~kg}$ ); café torrado em grãos em embalagem individual com atmosfera modificada (7 gramas); café solúvel em embalagem de vidro (50 e 100 gramas); capuccino tradicional (200 gramas) e capuccino diet (140 gramas) em lata; e cafés especiais em tubo cartonado a vácuo (500 gramas) e em lata a vácuo (250 gramas).

A empresa B implantou a linha de café gourmet em grãos torrados em embalagem com válvula de alívio de gases unidirecional há seis anos. A expansão do mercado de café gourmet para espresso e a possibilidade/necessidade de atuar neste mercado constituíram o grande motor para inclusão do produto no portfólio e uso da inovação. Posteriormente, a empresa passou a desenvolver o mercado, ofertando locação e venda de máquinas para café espresso. Atualmente, o produto café em grão para espresso representa $1,67 \%$ da sua produção mensal (100 sacas/mês) e aproximadamente $5,0 \%$ do seu faturamento.

Para a implantação da nova linha de produto, a empresa buscou auxílio junto aos seus fornecedores de embalagem e de máquinas e equipamentos. Como a indústria já possuía a linha de café em grãos torrado para moagem na hora, foram feitas adaptações de layout desta linha e aquisição de máquina de pesagem e empacotamento, com um custo estimado pelos entrevistados em R \$25.000,00. Os funcionários que passaram a atuar na linha de produto receberam treinamento realizado pela gerência industrial e fornecedor do equipamento. Não houve alterações no planejamento e programação da produção, pois este produto representava parcela pequena na quantidade produzida pela empresa. Para a impantação 
da nova linha foram empregados recursos próprios, não havendo necessidade de financiamento.

Inicialmente, a colocação da válvula era feita pelo fornecedor de embalagem. Posteriormente, em parceria com um fornecedor especializado de equipamentos e instrumentos, a empresa desenvolveu equipamento para colocação da válvula, passando a realizar esta operação. Segundo os entrevistados, o custo do equipamento foi de $\mathrm{R} \$ 1.500,00$ e a empresa passou a economizar $\mathrm{R} \$ 0,35$ por embalagem na época da instalação. Neste mesmo período, a empresa passou a adotar uma válvula similar àquela ofertada pela Goglio, porém de custo inferior. A menor eficiência de tal válvula implicou a redução de vida de prateleira do café espresso de um ano para três meses. Segundo os entrevistados, em função da abrangência regional de seu mercado, da programação da produção adotada e do rápido giro de produto, essa diminuição do prazo de validade não representou problema e possibilitou uma grande redução de custo para a empresa. O preço desta válvula é de $\mathrm{R} \$ 0,06$, contra US\$ 0,10 daquela fornecida pela Goglio. Observa-se que as ações da empresa sinalizam o enfoque em estratégias tanto de diversificação quanto de redução de custo.

O custo referente à válvula usada pela empresa representa $1,1 \%$ do preço de mercado, que, por se tratar de um produto de valor agregado maior, pode ser facilmente repassado ao preço do produto final. No entanto, para os entrevistados, isto não é possível no caso do produto tipo almofadinha, cujo preço é inferior e a margem de lucro é menor, em torno de 3\%. A empresa realizou alguns testes de colocação da válvula em embalagem de café torrado e moído tipo almofadinha, o que apresentou restrições técnicas segundo os entrevistados. A empresa estuda a adoção de uma nova válvula desgaseificadora (PLI-VALV) para estes produtos, no entanto, o custo unitário de $\mathrm{R} \$ 0,14$, em torno de $4 \%$ a $5 \%$ do preço do produto, inviabiliza sua adoção na opinião dos entrevistados. $\mathrm{O}$ custo do equipamento de colocação da válvula também é apontado pela empresa como um fator restritivo para adoção desta válvula.

\section{Resumo dos resultados dos casos}

O Quadro 2 apresenta um sumário dos resultados obtidos nos casos estudados. Como se observa, a existência de demanda e a estratégia de expansão de mercado atuaram como importantes fatores motivadores na adoção da inovação. Os fornecedores foram as fontes de informação para ambas as empresas. $\mathrm{O}$ processo de implantação e as alterações no processo produtivo apresentaram especificidades de acordo com a empresa. Destacam-se aspectos relacionados ao custo e aos arranjos 
de desenvolvimento de tecnologias similares em decorrência da inovação original e das estratégias de redução de custos.

QUADRO 2

Resumo dos resultados do estudo de casos

\begin{tabular}{|c|c|c|}
\hline & Empresa A & Empresa B \\
\hline Perfil da empresa & $\begin{array}{l}\text { Empresa de pequeno porte, } \\
\text { atuação em mercado regional, } \\
\text { estratégia de diversificação, } \\
\text { certificações (selo qualidade } \\
\text { Abic, ISO } 9000 \text { e Abrinq) }\end{array}$ & $\begin{array}{l}\text { Empresa de médio porte, } \\
\text { atuação em mercado regional, } \\
\text { estratégia de diversificação e } \\
\text { de custo, certificações (selo } \\
\text { qualidade Abic, ISO } 9000 \text { e } \\
\text { café orgânico) }\end{array}$ \\
\hline Tempo de adoção & 10 anos & 6 anos \\
\hline $\begin{array}{l}\text { Motivação para } \\
\text { adoção }\end{array}$ & $\begin{array}{l}\text { Reposicionamento de } \\
\text { produto/expansão de mercado } \\
\text { (café gourmet espresso) }\end{array}$ & $\begin{array}{l}\text { Expansão de mercado (café } \\
\text { gourmet espresso) }\end{array}$ \\
\hline Fonte de informação & Fornecedor de embalagem & $\begin{array}{l}\text { Fornecedores de embalagem } \\
\text { e de equipamentos e instru- } \\
\text { mentos }\end{array}$ \\
\hline $\begin{array}{l}\text { Implantação e } \\
\text { alteração no processo }\end{array}$ & $\begin{array}{l}\text { Linha de produção já } \\
\text { existente. Implantação } \\
\text { sem mudanças de layout e } \\
\text { aquisição de equipamentos. } \\
\text { Alterações no planejamento e } \\
\text { programação da produção. }\end{array}$ & $\begin{array}{l}\text { Adaptações de layout de li- } \\
\text { nha de produção existente e } \\
\text { aquisição de equipamentos. } \\
\text { Desenvolvimento de equipa- } \\
\text { mento de colocação de válvula } \\
\text { junto a fornecedor. }\end{array}$ \\
\hline Impactos & $\begin{array}{l}\text { Expansão de mercado. } \\
\text { Agregação de valor. } \\
\text { Otimização de uso de recursos } \\
\text { humanos e equipamentos de } \\
\text { produção. }\end{array}$ & $\begin{array}{l}\text { Expansão de mercado. Agre- } \\
\text { gação de valor. Redução de } \\
\text { custo com adoção de equipa- } \\
\text { mento e tecnologia similar. }\end{array}$ \\
\hline
\end{tabular}




\section{Considerações finais}

A válvula de desgasificação unidirecional é uma inovação incremental que permitiu o reposicionamento de um produto existente, por meio da adoção de embalagem diferenciada. Os casos estudados demonstram dois dos principais fatores relacionados aos objetivos de mercado da empresa, que motivam a adoção de inovações: a ampliação de mercado ou sobrevivência num determinado segmento; e a melhoria de aspectos de qualidade do produto. De qualquer maneira, a demanda orienta a tomada de decisões das empresas, ou seja, a existência de mercado e o perfil do consumidor são elementos importantes para adoção de uma determinada inovação.

Como verificado nos estudos de caso, uma inovação pode resultar em alterações em todo o sistema produtivo, mesmo que em proporções pequenas, e arranjos para desenvolvimentos relacionados, como equipamentos ou produtos similares. Tais mudanças não somente repercutem no produto, mas também geram impactos indiretos, nem sempre facilmente quantificáveis, nos sistemas de produção.

A interação entre fornecedores apresenta-se como elemento importante para viabilizar a introdução de uma inovação no mercado, como pode ser observado nos casos estudados entre fornecedores de válvula e de embalagem convencional. Outro aspecto relacionado à difusão de tecnologias refere-se ao tempo de difusão da inovação e os aspectos condicionadores deste processo. A inovação pioneira em análise foi gerada e lançada pela empresa na década de 1960 no país de origem e somente nos anos 1990 passou a ser adotada no Brasil por empresas de torrefação de café. Neste processo de difusão, também se observa o desenvolvimento de imitações e de produtos similares em decorrência de redução de custos e adequações do mecanismo a outros produtos alimentícios.

\section{Referências bibliográficas}

ALLARCON, B.; HOTCHKISS, J. H. The effect of FreshPax oxygen-absorbing packets on the shelf-life of foods. New York: Cornell University/Department of Food Science, 1993, p. 1-7 (Technical Report).

ARUNDEL, A. et al. The future of innovation measurement in Europe: concepts, problems and practical directions. Oslo: NIFU STEP, 1998 (IDEA Paper Series, n. 3). Disponível em: <http://www.step.no/old/Projectarea/IDEA/Idea3.pdf>. Acesso em: 23 fev. 2007. 
BONOMA, T. V. Case research in marketing: opportunities, problems, and process. Journal of Marketing Research, v. 22, p. 199-208, May 1985.

BOSSI, M. G. Capacitação para o processo de desenvolvimento de produto alimentício: estudo de caso. 2003. 143 f. Dissertação (Mestrado em Engenharia de Produção) - Centro de Ciências Exatas e Tecnologia, Universidade Federal de São Carlos, São Carlos, 2003.

BRASIL. Ministério da Saúde. Secretaria de Vigilância em Saúde. Vigilância epidemiológica das doenças transmitidas por alimentos no Brasil, 1999-2004. Boletim Eletrônico Epidemiológico, Brasília, v. 5, n. 6, p. 1-7, 2005. Disponível em: <http://portal.saude.gov.br/portal/ arquivos/pdf/bol_epi_6_2005_corrigido.pdf >. Acesso em: 10 mar. 2009.

BRYMAN, A. Research methods and organization studies. London: Unwin Hyman, 1989.

CABRAL, J. E. O. Natureza da inovação tecnológica na indístria de alimentos do Brasil. Fortaleza: Embrapa Agroindústria Tropical, 2001. Disponível em: <http://fgvsp.br/iberoamerican/Papers/0351_artigo\%20iberoamerican\%20Natureza\%20da\%20 Inovaçāo\%20 Tecnológica\%20na\%20Industria\%20de\%20Alimentos\%20do\%20Brasil.pdf>. Acesso em: 12 dez. 2007.

CENTERS FOR DISEASE CONTROL AND PREVENTION/ DEPARTMENT OF HEALTH AND HUMAN SERVICE. Foodborne illness. 2005. Disponível em: <http://www. cdc.gov/ncidod/dbmd/diseaseinfo/foodborneinfections_g.htm> Acesso em: 15 nov. 2007.

CRESWELL, J. W. Combined qualitative and quantitative designs. In: CRESWELL, J. W. Research design: qualitative and quantitative approaches. London: Sage Publications, 1997, 173-192p.

CRUZ, R. S. Efeito da adição de $\mathrm{CO}_{2}$ no processamento de macarrão tipo massa fresca. 2000. 68 f. Dissertação (Mestrado em Ciência e Tecnologia de Alimentos) - Departamento de Tecnologia de Alimentos, Universidade Federal de Viçosa, Viçosa, 2000.

CUNHA L. R. et al. Desenvolvimento e avaliação de embalagem ativa e incorporação de lactase. Ciência e Tecnologia de Alimentos, v. 27, p. 23-26, 2007.

DOSI, G. The nature of the innovative process. In: DOSI, G.; FREEMAN, C.; NELSON, R.; SILVEMBERG, G., SOETE, L. (Eds.). Technical change and economic theory. London: Pinter, 1988.

ETC GROUP. Down on the farm: the impact of nano-scale technologies on food and agriculture. Ottawa: ETC Group, 2004. 74p. Disponível em: <http://www.etcgroup.org/en/ materials/publications.html?pub_id=80> Acesso em: 15 nov. 2007.

FAO/WHO. Global forum of food safety regulators Marrakech: Summary Report. 2002. Disponível em: <http://www.who.int/foodsafety/publications/fs_management/global_forum/en/ index.html.> Acesso em: 15 nov. 2007 
FAPEMIG. Embalagens ativas. Revista Minas Faz Ciência, n. 9, dez. 2001/fev. 2002. Disponível em: < http://revista.fapemig.br/materia.php?id=159>. Acesso em: $10 \mathrm{dez} .2008$.

FORZA, C. Survey research in operations management: a process-based perspective. International Journal of Operations \& Production Management, v. 22, n. 2, p. 152-194, 2002.

FREEMAN, C.; SOETE, L. The economis of industrial innovation. London: Pinter, 1997.

FULLER, W. G. New food product development: from concept to marketplace. Florida: CRC Press LLC, 1994.

FURTADO A. T.; CARVALHO, R. Q. Padrões de intensidade tecnológica da indústria brasileira: um estudo comparativo com os países centrais. São Paulo em Perspectiva, v. 19, n. 1, p. 70-84, jan./mar. 2005.

IBGE. Pesquisa de Inovação Tecnológica - Pintec 2005. Rio de Janeiro: IBGE, 2007.

Pesquisa Industrial de Inovação Tecnológica - Pintec 2003. Rio de Janeiro: IBGE, 2005.

Pesquisa Industrial de Inovação Tecnológica - Pintec 2000. Rio de Janeiro: IBGE, 2002.

ILORI, M. O.; OKE, J. S.; SANNI, S. A. Management of new product development in selected food companies in Nigeria. Technovation, v. 20, p. 333-342, 2000.

JUNG, C. F. Metodologia científica - ênfase na pesquisa tecnológica. 2003. Disponível em: <http://www.jung.pro.br >. Acesso em: 21 ago. 2007.

KAPLAN, R. S.; NORTON, D. P. Transforming the balanced scorecard from performance measurement to strategic management: part I. Accounting Horizons, v. 15, n. 1, p. $87-$ 10, mar. 2001.

KRUIJF, N. et al. Active and intelligent packaging: applications and regulatory aspects. Food Additives and Contaminants, v. 19, Supplement 1, p. 144-162, Apr. 2002.

KUMPE, T. K.; BOLWIJN, P. T. Toward the innovative firm. Challenge for R\&D Management. Research Technology Management, v. 37, p. 38-44. Jan./Feb. 1994.

MESTRINER, F. Design de embalagens. 2. ed. São Paulo: Prentice Hall, 2005.

Oportunidades para embalagens de PVC. 2007. Disponível em: <http://www. institutodopvc.org/congresso2/FabioMestriner.pdf> Acesso em: 10 out. 2007.

MINISTÉRIO DA SAÚDE. Sistema de Informação sobre Mortalidade. Disponível em: <http://www.datasus.gov.br/catalogo/sim.htm>. Acesso em: 14 ago. 2007.

MORAES, R. BrasilPack 2006: feira cresce e expōe flexografia. Plástico Moderno, v. 377, mar. 2006. Disponível em: <http://www.plastico.com.br/revista/pm377/brasilpack1.html> Acesso em: 25 jan 2008. 
OECD. Manual de Oslo: diretrizes para coleta e interpretação dos dados sobre inovação. 3. ed. Trad. Finep. São Paulo: Finep, 2005. Disponível em: <http://www.finep.gov.br/imprensa/ sala_imprensa/manual_de_oslo.pdf>. Acesso em: 14 ago. 2007.

OLIVEIRA, L. M.; OLIVEIRA, P. A. P. L. V. Revisão: principais agentes antimicrobianos utilizados em embalagens plásticas. Brazilian Journal of Food Technology, v. 7, n. 2, p.161-165, jul./dez. 2004.

PAVITT, K. Sectoral patterns of technical changes: towards a taxonomy and a theory. Research Policy, v. 13, n. 6, p. 343-373, Dec. 1984.

PINTO J. S.; ANHOLON, R. A. Inovação nas empresas e a necessidade de novos paradigmas em indicadores de desempenho. In: SEMINÁRIOS EM ADMINISTRAÇĀO FEA-USP, 7, 2004, São Paulo. Anais... São Paulo: USP, 2004. Disponível em: <http:// www.ead.fea.usp.br/Semead/7semead/paginas/artigos\%20recebidos/PGT/PGT01_A_inova\%E7\%E3o_nas_empresas.PDF> Acesso em: dez. 2008.

ROONEY, M. L. Overview of active food packaging. In: ROONEY, M. L. (Ed.). Active food packaging. London: Blakie Academic and Professional,. 1995, p. 1-37.

SANTINI, G. A. et al. Conceitos de inovação no agronegócio. In: ZUIN, F. S.; QUEIROZ, T. R. (Orgs.). Agronegócio: gestão e inovação. São Paulo: Saraiva, 2006, p. 219-250.

SANTINI, G. A.; SOUZA, R. C.; QUEIROZ, T. R. Conceitos de inovação no agronegócio. In: ZUIN, L. F.; QUEIROZ, T. R. (Orgs.) Agronegócios: gestão e inovação. 1 ed. São Paulo: Saraiva, 2006, v. 1, p. 220-250.

SCHUMPETER, J. A. Teoria do desenvolvimento econômico: uma investigação sobre lucros, capital, credito, juro e o ciclo econômico. 3. ed. São Paulo: Abril Cultural, 1982 (Os Economistas, v. 33).

. Capitalismo, sociedade e democracia. São Paulo: Abril Cultural, 1988.

SILVA, C. A. B.; BATALHA, M. O. Competitividade em sistemas agroindustriais: metodologia e estudo de caso. In: WORKSHOP BRASILEIRO DE GESTÃO DE SISTEMAS AGROAlimentares, 2, 1999, Ribeirão Preto. Anais... Ribeirão Preto: Pensa/FEA/ USP, 1999, p. 9-19.

SOARES, N. F. F. Embalagens ativas com produtos cárneos. In: SIMPÓSIO DE TECNOLOGIA E INDUSTRIALIZAÇÃO DE CARNES, 4, 2007, São Paulo. Palestra disponibilizada pela autora após realização do evento.

SOARES, N. F. F. et al. Embalagem ativa na conservação de alimentos. In: AZEREDO, H. M. C. (Org.). Fundamentos de estabilidade de alimentos. Fortaleza: Embrapa Agroindustrial Tropical, 2004, p. 167-189. 
SOUSA, W. H.; VASCONCELLOS, E. P. G. A competitividade das empresas do setor de embalagens para alimentos: um estudo de caso. Revista de Administração de Empresas, São Paulo, v. 40, n. 1, p. 88-100, jan./mar. 2000.

STAL, E. Inovação tecnológica, sistemas nacionais de inovação e estímulos governamentais à inovação. In: MOREIRA, D. A.; QUEIROZ, A. C. (Coord.). Inovação organizacional e tecnológica. São Paulo: Thomson Learning, 2007, p. 24-53.

TULL, D. S.; HAWKINS, D. I. Marketing research, meaning, measurement and method. London: Macmillan Publishing Co, 1976.

VERMEIREN, L. et al. Developments in the active packaging of foods. Trends in Food Science and Technology, v. 10, n. 3, p. 77-86, mar. 1999.

YIN, R. Case study research: design and methods. Thousand Oaks: Sage Publications, 1994.

ZALTMAN, G.; DUNCAN, R.; HOLBECK, J. Innovations and organizations. New York: Wiley Interscience, 1973.

ZALTMAN, G.; LIN, N. On the nature of innovations. American Behavioral Scientist, p. 651-673, 1971 .

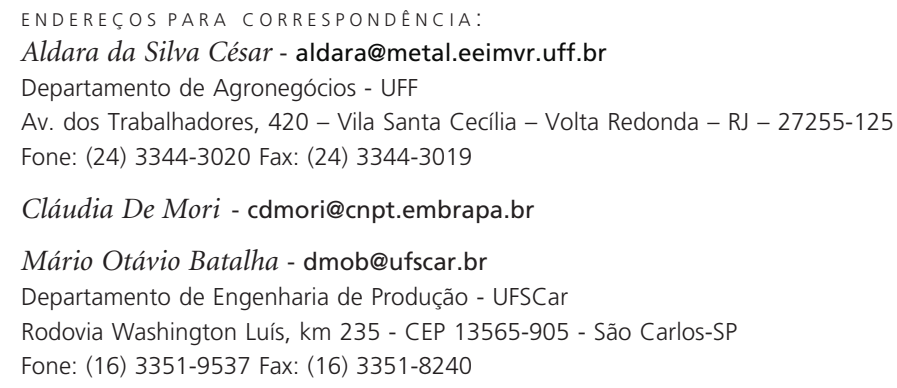

